\title{
Pericardial Sarcoma
}

National Cancer Institute

\section{Source}

National Cancer Institute. Pericardial Sarcoma. NCI Thesaurus. Code C147098.

A rare sarcoma that arises from the pericardium. The two most common types are angiosarcoma and synovial sarcoma. Patients present with symptoms related to pericardial effusion. 